\title{
Sciatic nerve palsy after total hip replacement
}
A. Sosna,
D. Pokorny,
D. Jahoda

From the 1st

Orthopaedic Clinic,

1st Medical Faculty,

Charles University,

Prague, Czech

Republic
A. Sosna, MD, DrSc, Professor

D. Pokorny, MD, PhD

D. Jahoda, MD, PhD

I. Ortopedická klinika, I.LF

UK, FN Motol V úvalu 84,

Praha 5, Czech Republic

Correspondence should be sent to Professor A. Sosna; e-mail: sosna.orto@email.cz

C2005 British Editorial Society of Bone and Joint Surgery

doi:10.1302/0301-620X.87B8. $16550 \$ 2.00$

$J$ Bone Joint Surg [Br] 2005;87-B:1140-1.

Received 5 November 2004;

Accepted after revision

20 April 2005

\section{We report a case of sciatic nerve palsy following total hip replacement which has lead to a novel hypothesis to account for this complication.}

Sciatic nerve palsy after total hip replacement (THR) may result from direct injury of the nerve. ${ }^{1-6}$ Occasionally, a palsy may occur without an obvious cause. ${ }^{4}$ The case we now report is the basis for an hypothesis to account for some idiopathic palsies.

\section{Case report}

A right THR was performed on a 56-year-old woman at another hospital. Immediately after the procedure, a sciatic palsy developed. Four weeks later, the patient fell and loosening of the acetabular component was diagnosed. She was referred to our care at four months. Neurophysiological tests were performed and a palsy affecting both the medial and the lateral components of the sciatic nerve was identified. Neither was complete although the lateral component was more severely affected than the medial.

At revision of the acetabular component (Fig. 1), a variant of the relationship between the sciatic nerve and the piriformis muscle was found. The lateral part of the nerve penetrated the muscle and the medial half passed distal to it (Fig. 2). The piriformis had retracted after an external rotator tenotomy performed at the primary surgery. The nerve was stretched, adherent to the muscle and embedded in immature scar tissue. Part of the piriformis was resected to release that part of the nerve passing through the muscle while the remainder of the nerve was dissected from scar tissue. After the operation, sciatic nerve function started to improve and gradually progressed to full recovery. Nerve conduction one year after the revision procedure showed normal function.

\section{Discussion}

Variants of the normal relationship between the piriformis muscle and the sciatic nerve, involving the penetration of the muscle either by the lateral part or the whole nerve occur in about $15 \%$ of cadavers. These variants first

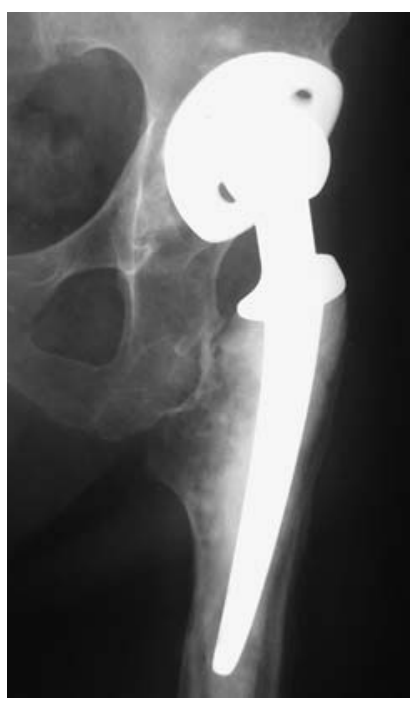

Fig. 1a

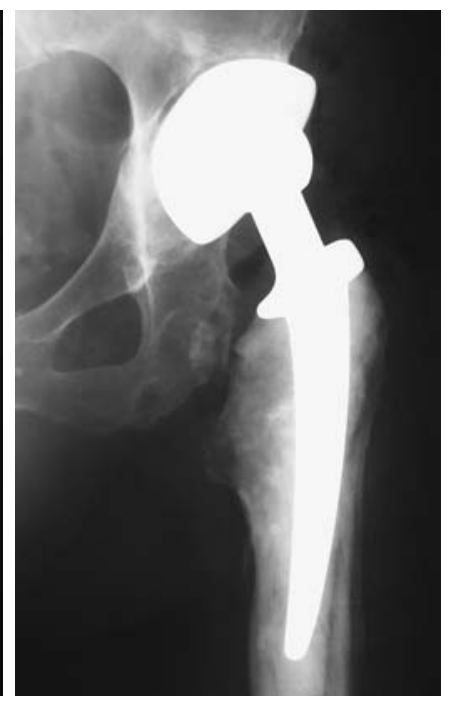

Fig. 1b
Radiographs showing a) loosened acetabular component and b) after revision. 


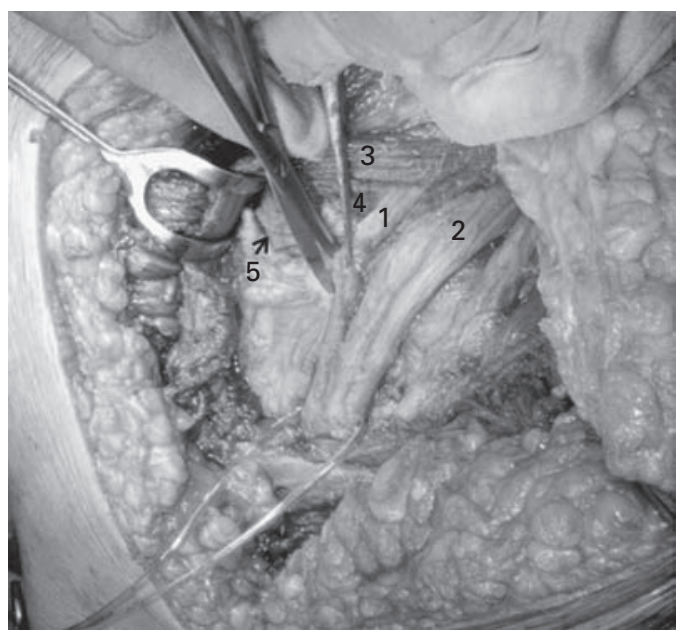

Fig. 2a

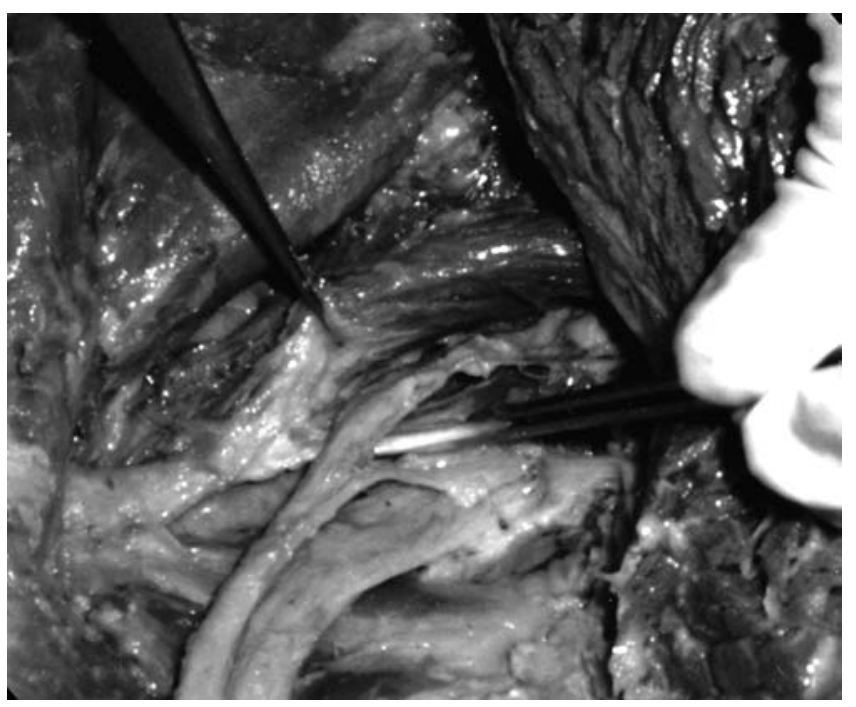

Fig. 3

A dissection of a Type IV (Beaton) variant as described in this case. The forceps grasp the upper and lower parts of the piriformis muscle. The sciatic nerve passes partly through and partly below the muscle.

described in $1897,{ }^{7}$ were classified in $1937^{8}$ and are included in textbooks of anatomy. ${ }^{9}$ This report is concerned with the most common variant ${ }^{8,10,11}$ (Fig. 3).

We suggest that in some of the currently inexplicable sciatic nerve palsies after THR the piriformis tendon may have been divided at operation (as in our case) and in the presence of an anatomical variant involving the penetration of piriformis by the whole sciatic nerve, or only its lateral fibres, the subsequent medial retraction of the piriformis muscle may drag the penetrating part of the nerve with it, damaging the nerve in the process (Fig. 2).
Although this mechanism may have accounted for our case, the frequency could only be gauged by exploration of other hips in cases of sciatic nerve palsy after THR and piriformis tenotomy. No other case has come under our care. We put forward this hypothesis in the hope that surgeons may explore apparently idiopathic lesions in the future. If part or the whole nerve was found to penetrate the muscle, division or resection of the muscle might validate the hypothesis and promote recovery, as it did in this case.

\footnotetext{
This paper was supported by grant MZO 00064203-6604.

No benefits in any form have been received or will be received from a commercial party related directly or indirectly to the subject of this article.
}

\section{References}

1. Edwards BN, Tullos HS, Noble PC. Contributory factors and etiology of sciatic nerve palsy in total hip arthroplasty. Clin Orthop 1987;218:136-41

2. Navarro RA, Schmalzried TP, Amstutz HC, Dorey FJ. Surgical approach and nerve palsy in total hip arthroplasty. J Arthroplasty 1995;10:1-5.

3. Nercessian 0, Piccoluga F, Eftekhar NS. Postoperative sciatic and femoral nerve palsy with reference to leg lengthening and medialization/lateralization of the hip joint following total hip arthroplasty. Clin Orthop 1994;304:165-71

4. Schmalzried TP, Amstutz HC, Dorey FJ. Nerve palsy associated with total hip replacement: five factors and prognosis. J Bone Joint Surg [Am] 1991;73-A:1074-80.

5. Simon JP, Van Delm I, Fabry G. Sciatic nerve palsy following hip surgery. Acta Orthop Belg 1993;59:156-62.

6. Zechmann JP, Reckling FW. Association of preoperative hip moton and sciatic nerve palsy following total hip arthroplasty. Clin Orthop 1989;241:197-9.

7. Parsons FG, Keith A. Sixth Annual Report of the Committee of Collective Investigation of the Anatomical Society of Great Britain and Ireland. J Anat and Physiol 1897; 31:31-44

8. Beaton LE, Anson JB. The relation of the sciatic nerve and of its subdivisions to the piriformis muscle. Anat Rec 1937;70 (Suppl 1):1-5

9. Agur AMR, Dalley AF. Grant's atlas of anatomy. 11 Edition, Philadelphia: Lippincott, Williams \& Wilkins, 2005:372.

10. Pokorny D, Sosna A, Veigl D, Jahoda D. Anatomical variability of the relationship of pelvitrochanteric muscles and sciatic nerve. Acta Chir Orthop Traum Cech 1998;65: 336-9 (in Czech)

11. Lee CS, Tsai TL. The relation of the sciatic nerve to the piriformis muscle. Taiwan $Y_{i}$ Xue Hui Za Zhi 1974;73:75-80 (in Chinese). 